\title{
Arranjos Com Repetição E Simulações Probabilísticas: Obstáculos De Aprendizagem
}

\section{Arrangements With Repetition And Probabilistic Simulations: Learning Obstacles}

\author{
Giselle Corrêa de Souza* \\ Instituto de Ciências Exatas e Naturais do Pontal / Universidade Federal de \\ Uberlândia (ICENP/UFU) \\ Leandro de Oliveira Souza* \\ Instituto de Ciências Exatas e Naturais do Pontal / Universidade Federal de \\ Uberlândia (ICENP/UFU)
}

\begin{abstract}
Resumo
Ao utilizar atividades empíricas para simular problemas, parece haver alguns entraves por parte dos alunos ao raciocinar sobre as posições inversas nos arranjos com repetição. Percebeu-se o fato durante um curso ministrado em uma Instituição Pública Federal, após a simulação de um jogo. Esse recorte de pesquisa visa discutir situações didáticas que podem trazer obstáculos para que alunos do Ensino Médio contabilizem as somas de parcelas diferentes ou iguais em ordem inversa, ao estimar probabilidades. Como pressuposto metodológico, a pesquisa pautou-se na investigação ação. A coleta de dados deu-se no decorrer das aulas por meio de vídeo e audiogravação, cópia das anotações dos estudantes e registro em diário de campo dos pesquisadores. As anotações foram feitas durante e após a interação com os estudantes. Os resultados apontam que conceitos matemáticos desenvolvidos na fase de escolarização podem influenciar concepções equivocadas que alunos apresentam, quando raciocinam sobre combinatória e, consequentemente, sobre probabilidades de eventos ocorrerem.
\end{abstract}

Palavras-chave: Probabilidade, Raciocínio combinatório, Simulações empíricas, Investigação ação, Arranjo.

\begin{abstract}
By using empirical activities to simulate problems, there seems to be some hindrance on the part of students in reasoning about inverse positions in repetitive arrangements. It was noticed during a course given at a Federal Public Institution, after a simulation of the game craps. This research was carried out in order to understand what prevented high school students from accounting for the sums of different or equal parcels in reverse order, when estimating probabilities. As a methodological assumption, the research was based on an investigative class research. The data collection took place during the lessons through video and audio-recording, a copy of the students' the researchers' notes. The notes were taken during and after interaction with the students. The results point out that mathematical concepts

\footnotetext{
* Tecnóloga em Análise e Desenvolvimento de Sistemas / Instituto Federal de Educação, Ciência e Tecnologia do Triângulo Mineiro - campus Ituiutaba (IFTM). Estudante de Licenciatura em Matemática pelo Instituto de Ciências Exatas e Naturais do Pontal / Universidade Federal de Uberlândia (ICENP/UFU). Ituiutaba, Minas Gerais, Brasil. E-mail: gih.itba@gmail.com.

** Doutor em Ensino de Ciências e Matemática / Universidade Cruzeiro do Sul (UNICSUL). Professor Adjunto da Universidade Federal de Uberlândia (ICENP/UFU), Ituiutaba, Minas Gerais, Brasil. E-mail: olilean@gmail.com.
} 
developed since the first years of the schooling phase can influence misconceptions that students present, when they reason about combinatorial and, consequently, about probability of events occurring.

Keywords: Probability, Combinatorial Reasoning, Empirical Simulations, Investigation Action, Arrangement.

\section{Introdução}

No Ensino Médio é esperado que estudantes determinem a probabilidade de um evento ocorrer, construindo distribuições para espaços amostrais simples. Isso envolve algumas habilidades, e uma delas é o conhecimento sobre combinatória, permutação e princípios de contagem (Batanero \& Sanchez, 2005). A combinatória é mais do que uma ferramenta para o cálculo de probabilidades, ela também é utilizada em outros campos da Matemática, como na teoria dos números e grafos, na topologia, nas pesquisas operacionais, nas ciências da computação, na inteligência artificial, na comunicação, na genética e na estatística. O grande entrave é que a capacidade combinatória de resolução de problemas nem sempre é alcançada na Educação Básica.

Para estudantes de Ensino Médio, escolher entre diferentes métodos de contagem para aplicá-los, ao resolver problemas de combinação, não é uma tarefa trivial, e isso se deve às peculiaridades que cada tipo de problema apresenta. De acordo com Godino, Batanero e Roa (2005), os estudantes precisam apoiar-se em diferentes definições de objetos matemáticos para resolver situações que envolvem contagem, tais como configuração de combinatória, partição, arranjo, grupo, subconjunto, parâmetros, permutações, etc. A aplicação dessas definições e os conceitos de combinatória empregados surgem como resultado de pessoas realizando ações. Algumas dessas ações referem-se a ordenar um grupo de objetos, selecionar amostras, fazer partições e refletir sobre essas ações.

Por exemplo, três problemas com pequenas modificações e que tratam do mesmo objeto necessitam de ferramentas e ações diferentes para serem resolvidos: os de combinação são aqueles nos quais a ordem do agrupamento dos elementos do(s) conjunto(s) não gera possibilidades diferentes. Exemplo: Beatriz sorteará dois livros idênticos para presentear duas de suas sete amigas. Entre elas, sortear Laura e Luana seria o mesmo que sortear Luana e Laura, pois nesse caso as duas ganhariam o mesmo livro. Nas situações que envolvem arranjo e permutação, a ordem do agrupamento dos elementos de um conjunto gera novas possibilidades. Partindo do mesmo problema, um caso de permutação seria Beatriz realizar um sorteio de sete livros diferentes entre suas sete amigas; e em uma situação de arranjo Beatriz poderia realizar 
o sorteio de dois livros diferentes para presentear duas de suas sete amigas. O que diferencia arranjo e permutação é que nesta última todos os elementos do(s) conjunto(s) precisam ser agrupados e contabilizados - no caso, sete amigas e sete livros; e em arranjos não existe essa necessidade, poderiam ser sete amigas e um menor número de exemplares de livros com títulos diferentes.

De acordo com Pessoa e Borba (2010), a dificuldade dos estudantes, ao raciocinar sobre problemas de permutação e arranjo, "reside em organizar todos os elementos em ordens variadas" (p. 19). Analogamente, Souza e Lopes (2011) e Azevedo, Calheiros e Borba (2013) relataram que estudantes dos Ensinos Fundamental e Médio precisam de estímulos para perceber que, em situações que envolvem arranjo com repetição, agrupamentos de elementos inversos devem ser contabilizados.

A partir desta problemática, procuramos refletir (por meio de atividades empíricas e simulações) sobre quais obstáculos levam estudantes a desprezarem associações aditivas inversas em um problema de arranjo com repetição e probabilidade. Os relatos e a análise expostos nesta pesquisa surgiram a partir dos dados coletados durante um curso que foi proposto com viés investigativo sobre a linha de raciocínio desenvolvida pelos estudantes. A coleta de dados foi feita por meio de vídeo e audiogravação, observação com anotação em diário de campo e material produzido pelos discentes.

Neste artigo discutimos como a falta de compreensão de conceitos matemáticos de contagem, trabalhados na Educação Básica, influencia no cálculo de probabilidades e ajuda a subestimá-lo. A análise mostra que é necessário compreender como determinadas situações didáticas orientamconduzem o raciocínio dos estudantes. Verificamos que o contexto e a natureza do elemento empregado no problema podem ter influência direta na interpretação do modelo a ser utilizado pelos estudantes.

\section{Erros De Arranjo E A Influência Na Estimativa De Probabilidades}

De acordo com English (2005), a combinatória é um dos mais antigos ramos da matemática discreta, que remonta ao século XVI, quando os jogos de azar tiveram um papel fundamental na vida da sociedade. Para fornecer uma teoria para esses jogos, foram criadas técnicas de contagem específicas a partir de ideias matemáticas. Desde então, a combinatória tornou-se uma ferramenta importante para vários campos da Matemática, principalmente para o cálculo de probabilidades. 
Apesar de sua importância no currículo de Matemática, a combinatória continua a ser negligenciada, particularmente no Ensino Fundamental e no que se refere ao trabalho com materiais concretos e atividades empíricas. Batanero e Sanchez (2005) identificaram uma série de conceitos e procedimentos que são importantes no processo de ensino da combinatória e devem ser considerados quando se avalia a aprendizagem. Esses conceitos são sobre modelos de amostragem, procedimentos lógicos de classificação, enumeração sistemática, inclusão/exclusão e recorrência. Eles também são essenciais para lidar com situações que envolvem problemas probabilísticos. Outro procedimento básico é o uso de diagramas de árvores para a determinação de um espaço amostral.

Segundo algumas pesquisas (Batanero, Godino, \& Navarro-Pelayo, 1997; Eizenberg \& Zaslavsky, 2004; English, 2005), os estudantes encontram muita dificuldade na resolução de problemas combinatórios e alguns fatores contribuem para essas dificuldades. Elas se dividem e diferem em alguns aspectos, como: tipo ou operação, ou seja, decidir entre arranjo, permutação ou combinação; natureza dos elementos a serem combinados - números, letras, pessoas, objetos e códigos; e modelo combinatório implícito, ou seja, seleção, distribuição e partição (Eizenberg \& Zaslavsky, 2004).

Se o sujeito não for capaz de raciocinar enumerando elementos de um conjunto, usará a ideia de probabilidade apenas em casos de experimentos muito elementares (Navarro, Batanero, \& Godino, 1996). O raciocínio combinatório, de acordo com Borba, Rocha e Azevedo (2015), é um modo de pensar que pode ser utilizado em situações nas quais se analisam determinados conjuntos, com objetivo de agrupar seus elementos. Portanto, em problemas de análise combinatória e probabilidade, a contagem vai além de uma mera enumeração de objetos expostos; é necessário atender a critérios específicos de escolha e/ou ordenação.

O resultado das dificuldades faz com que, ao resolver problemas de combinatória e determinar critérios para enumerar os dados, os estudantes cometam diferentes tipos de erros e, de acordo com Navarro et al. (1996), podem: trocar o tipo de modelo ou técnica necessária para resolver um problema; confundir os conceitos de combinação, arranjo e permutação, considerando a ordem dos objetos quando ela é irrelevante e também o contrário (erros de ordem); não considerar a possibilidade de repetir os elementos quando é possível fazê-lo, e o contrário; enumerar de modo não sistemático as soluções do problema, de forma que não consigam encontrar todas as soluções para ele; dar uma resposta intuitiva, a partir do senso comum, sem justificativa; e/ou interpretar ou construir de maneira equivocada um diagrama de árvores. 
A maioria dos problemas que envolvem conceitos de probabilidade (Batanero et al., 1997) está ligada à dificuldade com o raciocínio combinatório, provocada pelos erros supracitados. Segundo Polaki (2005), os obstáculos para alunos do Ensino Fundamental ao listar o espaço amostral de um experimento são comuns e podem estar relacionados às experiências anteriores com fenômenos aleatórios. Por exemplo, um experimento feito por Fischbein e Gazit (1988, citado por Eizenberg e Zaslavsky, 2004) com estudantes do Ensino Fundamental mostrou que, antes de qualquer instrução, os problemas de permutação eram os mais difíceis para eles; ao quantificar os acertos dos alunos em uma lista de tarefas, o pesquisador considerou que os problemas de combinação eram mais facilmente resolvidos. No entanto, após instruções, ocorreu uma mudança, e os problemas de permutação tornaram-se mais fáceis. Isso pode ser explicado pelo fato de que a fórmula para o número de combinações seria mais complicada e, uma vez introduzida, as crianças abandonam suas estratégias empíricas intuitivas. Acreditamos que o mesmo ocorra com estudantes do Ensino Médio.

Neste texto analisamos um erro de ordem (arranjo com repetições) cometido por estudantes durante um curso que teve por objetivo permitir que os alunos pudessem, por meio de uma atividade empírica, desvincular simulações probabilísticas de crenças e sorte. Também discorremos sobre as inferências levantadas pelos sujeitos a partir do contexto do problema e de conceitos matemáticos evocados. No caso da atividade aplicada, alguns agrupamentos que deveriam ser contabilizados eram desprezados. Por exemplo, o elemento A de um conjunto associado ao elemento B de outro conjunto, na concepção dos alunos, era o mesmo que associar o inverso, B do primeiro conjunto a A do segundo, por isso eles não contabilizavam um dos eventos. Verificamos que este fato é recorrente nesse tipo de lição e, para que exista avanço na aprendizagem do discente, a intervenção do professor é fundamental.

\section{Metodologia}

Iniciamos o curso com a intencionalidade de fomentar mudanças de atitudes sobre a realidade dos estudantes em relação a conceitos de probabilidade. Entendemos que, para reflexão crítica sobre a práxis dos pesquisadores, havia a necessidade de estimular a interatividade, a discussão coletiva e a participação. Para tal, este estudo foi fundamentado em uma abordagem qualitativa com base em pressupostos metodológicos de investigação ação (Coutinho et al., 2009). Os dados foram analisados de forma interpretativa e emergiram de uma atividade empírica. Buscamos, por meio desta análise, entender quais obstáculos levaram os 
alunos a não considerar todos os elementos do espaço amostral e, portanto, a subestimar probabilidades.

Na perspectiva de investigação ação, Coutinho et al. (2009) descrevem a escola como "um terreno propício para gerar incertezas, anseios, problemas, conflitos comunicacionais e toda uma série de situações dinâmicas decorrentes da ação humana” (p. 2). Nesse ambiente, por meio das ações daqueles que se envolvem e dos que se desenvolvem, é possível fazer brotar da esfera social o que melhor se pode extrair dos diálogos. Ao acompanhar essa perspectiva e refletir sobre os diálogos, tivemos por foco investigar para agir, investigar e agir e, por último, investigar agindo.

A metodologia de investigação ação aproxima-se da nossa expectativa de compreender e abordar, durante o processo de ensino, as dificuldades que os estudantes possuem para resolver problemas probabilísticos que dependem de análise combinatória ou contagem. De acordo com Eizenberg e Zaslavsky (2004), uma maneira de fazer isso é identificar e estudar as habilidades metacognitivas dos alunos, especificamente por meio das soluções que eles trazem para a resolução do problema. Na perspectiva dos pesquisadores, verificar uma resposta a um problema combinatório é uma tarefa particularmente difícil no contexto da sala de aula e não necessariamente são asseguradas a identificação e a classificação de um erro, já que diferentes tipos de erros podem estar entrelaçados. A detecção de um erro também não produz obrigatoriamente uma maneira objetiva de alcançar uma solução correta. A estratégia de olhar para trás, compreendendo os caminhos cognitivos empregados na resolução do problema, desempenha um papel de estimular a criticidade. Agir dessa forma pode ajudar o professorpesquisador a detectar erros em nível local para que o aluno tenha mais cuidado; por outro lado, também pode ajudá-lo a identificar soluções em níveis mais globais.

Ao resolver problemas de contagem, o tipo do problema, a linguagem, as ações, os conceitos, as propriedades e os argumentos podem ser peculiares e particulares para uma pessoa específica, mas também podem ser compartilhados dentro de um grupo ou instituição (Godino et al., 2005). A nossa análise teve por foco compreender os argumentos individuais de cada estudante, mas, para isso, durante a interação na aula, compartilhamos respostas coletivas com objetivo de captar contra-argumentos dos alunos, ao resolver o problema.

A atividade que descrevemos neste texto foi desenvolvida e ocorreu em um curso com 40 horas de duração. Ela foi planejada para dois encontros, cada um com 1 hora e 30 minutos. Delineamos a formação dos estudantes a partir da temática "probabilidade e programação"; desta forma, os discentes inicialmente participariam de um jogo fazendo simulações (a fim de 
entender as regras e probabilidade envolvidas) para depois escreverem o respectivo código de programação. No contexto desta pesquisa identificamos que os discentes desprezavam os agrupamentos que deveriam ser contabilizados, o que nos levou a intervir sobre o processo de ensino-aprendizagem, ao invés de tentar apenas descrevê-lo para fins de estudo científico. Buscamos, então, ao intervir, entender o obstáculo que a tarefa causava nos estudantes; isso também nos ajudou a criar estratégias didáticas e refletir sobre a nossa práxis.

As aulas foram planejadas a partir das experiências pedagógicas vivenciadas pela primeira autora deste artigo, sobre programação em Java, e pelo segundo autor, sobre o ensino de Probabilidade. Os sujeitos da pesquisa foram 18 alunos do $1 .^{\circ}$ ano do curso técnico em Informática integrado ao Ensino Médio de uma escola federal no município de Ituiutaba - MG. A escolha dos sujeitos se deu por dois critérios: o bom aproveitamento em uma avaliação de conteúdos sobre o desenvolvimento de algoritmos em linguagem natural e lógica de programação; e a responsabilidade e o envolvimento com as atividades diárias do curso. Esses critérios foram utilizados para assegurar que os alunos participassem do projeto até o fim. Os estudantes e os responsáveis foram esclarecidos de que, além de participarem de um curso, os discentes também estariam envolvidos em uma pesquisa.

As atividades foram desenvolvidas e aplicadas pelos dois pesquisadores autores deste artigo. A coleta de dados foi feita por meio de vídeo e audiogravação, anotações em diário de campo e produção escrita dos alunos. Enquanto um dos pesquisadores desenvolvia a aula, o outro realizava anotações.

O planejamento de cada nova tarefa era feito após a análise dos dados coletados no encontro anterior. Essa forma de organizar as atividades deu-se porque o foco da análise estava sobre o raciocínio dos alunos. Embora houvesse evidências descritas na teoria sobre como os estudantes se comportariam, levamos em consideração a dificuldade em homogeneizar o desenvolvimento do raciocínio de cada sujeito; por isso fizemos uma análise sobre as reflexões verbalizadas por cada discente em diferentes momentos.

No primeiro encontro foi planejado que os estudantes, organizados em grupos, participariam de um jogo de azar com dados - conhecido como Craps (Deitel \& Deitel, 2010); anotariam os resultados da soma de dois dados (de seis faces cada) e também os "vencedores" e "perdedores" em cada rodada; e relatariam suas observações gerais sobre a atividade.

Você lança dois dados de 6 faces. Depois que os dados pararem de rolar, a soma dos pontos nas faces viradas para cima é calculada. Se a soma for 7 ou 11 no primeiro lance, você ganha. Se a soma for 2,3 ou 12 no primeiro lance (chamado "craps"), você perde (isto é, a "casa" ganha). Se a soma for $4,56,8,9$ ou 10 no primeiro lance, essa soma torna-se sua "pontuação". Para ganhar, você deve continuar a rolar os dados até "fazer 
sua pontuação" (isto é, obter um valor igual à sua pontuação). Você perde se obtiver um 7 antes de fazer sua pontuação. (Deitel \& Deitel, 2010, p. 168)

O jogo Craps é comum em cassinos e a terminologia "casa" é utilizada para indicar os momentos em que a casa de apostas ganha e, consequentemente, o jogador (aquele que aposta) perde. Adaptamos a "casa", durante a execução da atividade empírica, como sendo um dos alunos participantes do grupo; enquanto os demais eram de fato "jogadores".

Durante a interação na atividade, alguns discentes levantaram hipóteses relacionadas às regras, às probabilidades, às combinações, etc., e, ao final, percebemos que os alunos não compreendiam o que determinava as probabilidades de cada evento ocorrer. Então, planejamos, para o encontro seguinte, uma atividade que buscou levar os discentes a refletir sobre o espaço amostral e, consequentemente, identificar essas probabilidades.

Apesar de existir um planejamento inicial, foram as respostas dadas aos estímulos da docente que guiaram a execução das tarefas. Ou seja, houve flexibilidade na abordagem pedagógica e ocorreram imprevistos ao longo das tarefas; isso nos fez replanejar determinadas atividades e tomar rumos diferentes do previsto inicialmente. Não adotamos no curso uma perspectiva de sequência didática. A análise se deu sobre os momentos de interações dos estudantes com a professora pesquisadora e, também, dos alunos entre si.

\section{Uma Reflexão Sobre Enumeração E Arranjo Com Repetição A Partir Do Lançamento De Dois Dados No Jogo Craps}

No primeiro encontro, a professora dos estudantes, primeira autora deste artigo, foi a responsável por aplicar o jogo Craps. Enquanto isso ocorria, o segundo autor fazia anotações. O jogo foi executado de maneira empírica, com registro feito pelos discentes. Foram jogadas, por cada grupo de 4 alunos, 40 rodadas. Consideramos uma rodada o momento em que alguém ganha ou perde o jogo. Ao final de cada encontro, ambos os pesquisadores faziam conjuntamente uma análise da aula.

Ao acabar a experiência, esperávamos que os estudantes pudessem estimar as probabilidades de ocorrer cada soma das faces de dois dados lançados. Depois de algum tempo de interação - dos alunos entre eles, e destes com a professora -, notamos que as perguntas feitas pela docente induziam os discentes a observar as somas que apareciam com maior frequência. A observação tinha por base os registros dos estudantes (Figura 1). 


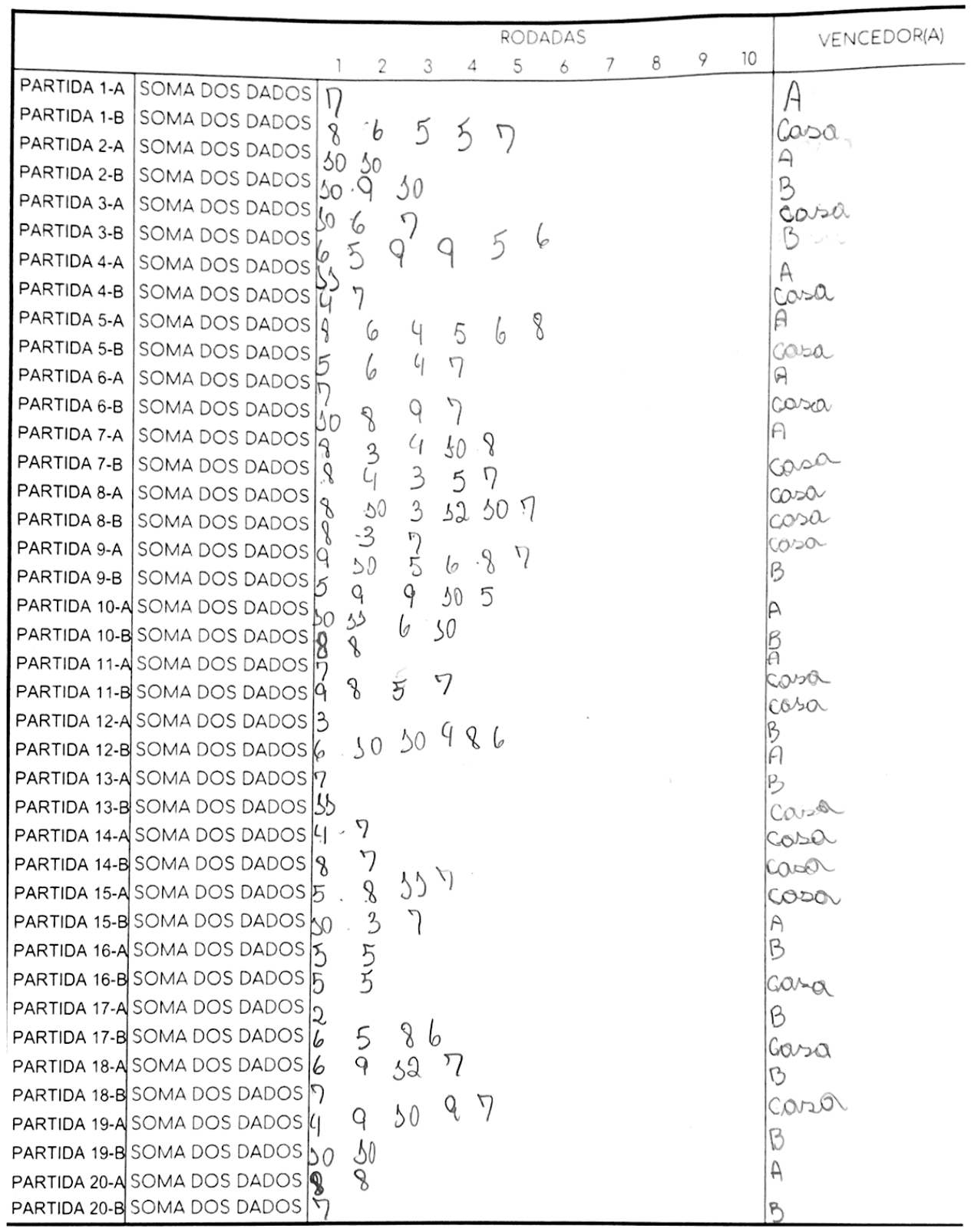

Figura 1. Registro dos alunos na primeira tarefa Fonte: Registro dos autores (2018)

Depois da interação, a professora pediu que os estudantes elaborassem um relatório sobre suas percepções acerca da atividade e, sem intenção aparente, recolheu os dados (objeto) das mãos dos alunos. A falta de material fez com que eles perdessem um referencial concreto. Isso lhes causou dificuldade para abstrair e enumerar quais agrupamentos das faces (duas a duas) seriam possíveis a partir de um lançamento. A pesquisadora percebeu e devolveu os dados aos discentes. No entanto, sem ajuda, os alunos não obtiveram sucesso em contabilizar os agrupamentos possíveis.

English (1993), ao conduzir um experimento com crianças de 7 a 12 anos de idade, 
verificou que não ter um procedimento sistematizado no início levou-os a traçar sequências de estratégias ao longo da resolução dos problemas. A análise das respostas das crianças revelou uma série de estratégias sofisticadas, começando por um comportamento de tentativa e erro até chegar a um procedimento combinatório mais sistemático.

Embora os estudantes do Ensino Médio não tenham tido sucesso ao contabilizar todos os agrupamentos possíveis, verificamos uma série de estratégias que poderiam ter sido bemsucedidas, se eles não tivessem cometido o erro de ordem descrito por Navarro et al. (1996). Esse erro de ordem pode estar atrelado: à diversidade de objetos que são envolvidos em atividades matemáticas, às múltiplas representações semióticas empregadas pelos estudantes durante a interpretação e a resolução dos problemas e à particularidade dos contextos e das circunstâncias psicossociais que determinam e relativizam a compreensão e a representação por parte dos alunos (Godino et al., 2005).

Ao analisar o relato dos estudantes, pós-atividade (Quadro 1), percebemos que dois dos quatro grupos não contabilizaram as somas que podem ser obtidas por agrupamentos de elementos em ordem inversa (ex. 4+3 e 3+4). É possível observar, na coluna à esquerda do quadro, que um grupo considerou a existência de agrupamentos formados com elementos distintos e, também, com elementos iguais. Além disso, levantou algumas hipóteses sobre a frequência de ocorrência dos eventos. Todavia, eles não identificaram quantos agrupamentos cada uma das somas possíveis produzia, e pautaram-se, portanto, na observação das frequências (visão frequentista) (Lopes \& Souza, 2016). No relato de outro grupo, à direita no Quadro 1, é possível notar que os alunos perceberam quais seriam as somas de maior frequência, mas igualaram as possibilidades de as somas 6,7 e 8 ocorrerem.

Quadro 1 - Relatório produzido por estudantes dos grupos 1 e 2, respectivamente, ao executar o jogo Craps

\begin{tabular}{|c|}
\hline $\begin{array}{l}\text { "Notamos que várias vezes os números } 9 \text { e } 10 \text { saíram, já os } \\
\text { números } 2 \text { e } 12 \text { apareceram apenas algumas vezes. } \\
\text { Propomos a ideia de que: números } 9 \text { e } 10 \text { saíam mais fácil } \\
\text { pelo fato de que os dados podem conter algarismos } \\
\text { diferentes entre eles; já no caso de } 2 \text { e } 12 \text {, os algarismos } \\
\text { necessitavam ser o mesmo entre os dados." }\end{array}$ \\
\hline notomos que vorios vezes os numeris $a$ e 10 sainom, \\
\hline fi'ts nimeres a e 12 gavicerom openss algumal vezet. \\
\hline Droponos a idica de que: números como qe 10 saióm mais \\
\hline foul pelo dato de que os dador podem conter algonismos \\
\hline diferentes entre eles. jo no coso de of e 12 , os alpa - \\
\hline rismes nexcessitovom ser o merno entu of dados. \\
\hline
\end{tabular}
"A partir da 2." rodada a casa tem mais chances de ganhar, já que o número 7 (junto com 6 e 8 ) possui mais combinações de serem obtidos."

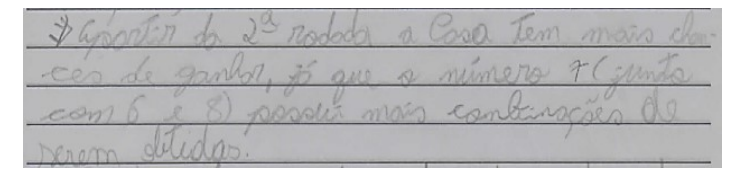

Fonte: Registro dos autores (2018)

As afirmações nas duas colunas mostram que a probabilidade de algumas somas 
ocorrerem foi subestimada. Por exemplo, as somas 6 e 7, respectivamente, poderiam ocorrer das seguintes formas: $1+5$ ou $5+1 ; 2+4$ ou $4+2$; ou $3+3$, ou seja, de cinco maneiras distintas; e $1+6$ ou $6+1 ; 2+5$ ou $5+2 ;$ e $3+4$ ou $4+3$, de seis maneiras distintas. Durante a interação, também verificamos que os alunos do grupo 2, da coluna à direita no Quadro 1, haviam deixado de considerar alguns dos agrupamentos inversos possíveis para cada soma; e, quando perceberam que subestimaram as probabilidades, questionaram se era necessário considerar o inverso de $3+3$, por exemplo.

Dos relatos dos quatro grupos formados, dois foram feitos a partir das observações empíricas. As outras equipes descreveram todas as possibilidades de ocorrência de cada soma; no entanto, não conseguimos identificar se todos os estudantes compreenderam o processo de agrupamento realizado.

Cada equipe jogou, no total, 40 ou 60 partidas, dependendo da quantidade de integrantes de cada grupo. Foram destinadas 20 a cada um dos jogadores contra a casa. Assim que todos finalizaram a anotação dos resultados, a professora pediu que fosse escrito um relatório sobre a atividade, que reportasse o que influenciava a vitória ou a derrota da casa; quais valores saíam com maior frequência e quais saíam com menor frequência; quais combinações geravam os valores mais frequentes; e o número total de vitórias da casa e de cada um dos jogadores. $\mathrm{O}$ relato do grupo 1 traz a seguinte observação:

Primeiramente a casa possui mais chances de ganhar, porque participa de todas as rodadas e os jogadores participam apenas da metade. Primeira rodada $\rightarrow$ as chances

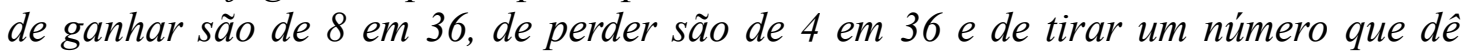
pontuação são de $24 \mathrm{em} \mathrm{36.} \mathrm{Na} \mathrm{segunda} \mathrm{rodada} \rightarrow$ as chances de perder são de $6 \mathrm{em}$ 36 se você tirou um número que dê pontuação. E as chances de você ganhar depende do número que você tirou na primeira rodada. (Relato escrito produzido pelo grupo 1, 2018)

O relatório demonstra que os alunos conseguiram identificar as combinações de cada soma para que obtivessem as chances de ganhar, perder ou continuar na primeira rodada. Percebemos a ligação realizada entre conceitos de probabilidade e a atividade empírica; e por isso acreditamos que pelo menos um elemento do trio tenha tido contato prévio com assuntos relacionados à probabilidade.

No decorrer do planejamento das atividades para a semana dois, levamos em consideração - por meio das observações e das interações feitas em sala e das gravações em áudio e vídeo - que seria necessário planejar uma aula que levasse os discentes a enumerar todos os agrupamentos possíveis para que cada uma das somas ocorresse. Para isso, já na execução da atividade, os alunos foram organizados em duplas e receberam um par de dados. 
Com o propósito de que os estudantes relembrassem as regras, a segunda autora as escreveu na lousa.

Depois de nos certificarmos de que os alunos haviam realmente compreendido para qual situação as somas os levariam, a pesquisadora fez uma intervenção, questionando os discentes se o jogo "é um jogo de sorte". Ao que os estudantes responderam: "sim”, “não”, "é mandinga", "é macumba". Poucos foram os que deram a segunda resposta (não). Então, a professora perguntou a eles quais as combinações que levariam à soma 7; e alguns começaram a verbalizar as possibilidades. Um deles questionou: "O inverso conta?"; e isso gerou dúvida nos demais. Souza e Lopes (2011) também identificaram esse obstáculo cognitivo durante a execução de uma atividade semelhante. Neste nosso caso, o questionamento não era esperado pela pesquisadora; e isso a levou a criar estratégias, paralelamente ao planejamento, para que a turma compreendesse que o agrupamento inverso influenciava na enumeração dos elementos do espaço amostral.

A estratégia utilizada foi pedir que cinco alunos ficassem em fila na frente da sala, como se estivessem em um caixa de um banco. Depois ela mudou a ordem dos sujeitos e perguntou: “É a mesma coisa?”; eles continuaram oscilando suas respostas acerca do agrupamento inverso. Percebemos que as reflexões dos discentes estavam acontecendo no entorno da soma; para eles, $4+3$ e $3+4$ representavam a mesma coisa (eles levavam em consideração a soma dos dados). Poucos argumentaram que as combinações eram diferentes.

Outra tentativa da professora foi entregar canetas e lápis (em quantidades diferentes) a um grupo e pedir que eles somassem o total de objetos. Após esta atividade, ela pediu que todos entregassem os itens para apenas uma estudante; perguntou se havia mudado algo na quantidade de elementos. Eles responderam que, para cada indivíduo do grupo, sim, mas o total, não. O segundo autor, que observava a aula, percebeu que a professora ficou sem estratégias no momento e frustrou-se por não conseguir convencer os estudantes a contabilizar a combinação inversa; isso foi confirmado (posteriormente) quando ambos os pesquisadores analisaram os dados coletados no diário de bordo e na videogravação realizada durante a atividade empírica.

Levantamos algumas hipóteses sobre os obstáculos que supostamente precisam ser superados: eles têm relação com conceitos matemáticos que são trabalhados desde a fase de escolarização. Um deles é o de conservação. Constatamos, pelos relatos de alguns alunos durante as tentativas da professora, que eles consideram que, independentemente da posição dos algarismos, a soma se conserva e, por isso, o inverso não precisa ser enumerado. Esse obstáculo vincula-se à natureza do elemento contabilizado - números (Eizenberg \& Zaslavsky, 
2004). Acreditamos que, se a natureza do objeto tivesse outras características, além da quantitativa, o obstáculo cognitivo seria mais facilmente superado.

Outro conceito matemático os levou a desprezar a combinação inversa dos elementos: a comutatividade na adição, pois a famosa frase (“a ordem das parcelas não altera a soma”), muitas vezes, durante a interação, foi utilizada pelos estudantes como argumento para justificar a sobreposição de elementos combinados.

Por último, supomos que a característica do jogo que atrelava o contexto dos agrupamentos à soma trouxe outra dificuldade, que foi a de tipo ou ordem, ou seja, escolher entre combinação, permutação ou arranjo, mesmo que de maneira empírica (Eizenberg \& Zaslavsky, 2004). Na nossa análise, não associamos o obstáculo cognitivo ao uso de fórmulas, como foi sugerido nas pesquisas supracitadas, até porque não apresentamos fórmulas aos alunos.

A dificuldade dos estudantes, mesmo executando uma atividade empírica, foi em decidir se deveriam ou não considerar alguns eventos na enumeração. Todos os argumentos levantados pelos alunos para não contabilizar o inverso tinham por foco os resultados obtidos pelas adições; por isso desprezam o processo de ordenação das parcelas. Batanero et al. (1997) levaram em consideração que não apenas o tipo (ou operação) do problema ou a natureza dos elementos trazem dificuldades aos estudantes, pois a instrução também afeta a interpretação do problema e direciona o tipo de erro. Houve tentativas de orientação da professora mas sem sucesso.

A partir dessa pesquisa e das conjecturas aqui relatadas, outra pergunta nos causou incômodo: será que em problemas de contagem e probabilidade que envolvessem variáveis qualitativas também surgiriam problemas com a enumeração do inverso e a repetição dos elementos? Essa é uma pergunta que pretendemos investigar em novos estudos e para tal delinearemos novos experimentos em um outro momento.

\section{Considerações Finais}

O objetivo deste artigo foi discutir situações que impedem sujeitos, quando expostos a simulações empíricas, de contabilizar associações aditivas inversas em um problema de arranjo com repetição e probabilidade. Tal impedimento foi percebido por nós, pesquisadores, ao desenvolver uma atividade de probabilidade com estudantes do Ensino Médio.

No primeiro encontro, momento em que ocorreu a primeira simulação empírica do curso, os alunos já haviam sido avisados sobre a pesquisa e os objetivos de apreenderem 
conceitos Matemáticos. Contudo, fizeram a atividade sem associar o jogo a algum conceito matemático, mesmo nos momentos em que havia intervenção da pesquisadora. Percebemos que os sujeitos começaram a refletir sobre a relação entre o jogo e a Matemática envolvida apenas após a finalização da tarefa, quando precisaram escrever um relatório sobre o que havia acontecido durante a aula.

Assim, para o segundo encontro, decidimos que novas atividades eram necessárias, a fim de que os discentes pudessem descobrir a relação existente entre a probabilidade e o jogo. Eles não sabiam se deveriam contabilizar o agrupamento inverso para enumerar os elementos do espaço amostral. A fim de permitir que descobrissem a resposta, a pesquisadora criou estratégias, não planejadas a priori, a fim de sanar as dúvidas dos alunos, no entanto não obteve sucesso. Entretanto, esse momento foi importante para que percebêssemos, em uma posterior análise, o modo como os estudantes acreditam que a contabilização de associações aditivas inversas deveria ocorrer.

Este estudo aponta que conceitos matemáticos desenvolvidos na fase de escolarização (ordenação, classificação e conservação) têm influência nas concepções equivocadas que alunos apresentam quando raciocinam sobre combinatória. Na resolução do problema, alguns estudantes utilizaram a abordagem frequentista para buscar respostas durante o jogo Craps, isso pode ter culminado em percepções equivocadas dos alunos. Sugere-se, nesses casos, que em algum momento da atividade, torna-se necessário fazer uma abordagem pedagógica da visão clássica da probabilidade. Estudar essa problemática faz-se necessário, porque os estudantes, quando cometem equívocos, passam a ter dificuldades ao resolver problemas de contagem em situações de incerteza.

Na situação relatada, as probabilidades de um evento ocorrer foram subestimadas por causa de erros de ordem. Quando isso ocorreu, criou-se um obstáculo para que os estudantes teorizassem sua prática, ao levantar possibilidades a partir do processo empírico.

No grupo pesquisado havia estudantes que formulavam suas respostas de acordo com os conceitos de probabilidade. Acreditamos que esses tenham passado, durante alguma fase escolar, por simulações empíricas. Essas simulações são importantes porque permitem que percebam os conceitos antes mesmo de passarem para formalização.

Esperamos, com esta análise, estimular o desenvolvimento de novas pesquisas. Aquelas que visem compreender como situações didáticas empíricas e simulações podem trazem benefícios para o raciocínio combinatório dos estudantes e, consequentemente, para o raciocínio probabilístico. 


\section{Referências}

Azevedo, J., Calheiros, J., \& Borba, R. (2013). Problemas combinatórios inversos resolvidos por alunos do $9 .^{\circ}$ ano do Ensino Fundamental e do $3 .^{\circ}$ ano do Ensino Médio. Revista Paranaense de Educação Matemática, 2, 41-62.

Batanero, C., Godino, J., \& Navarro-Pelayo, V. (1997). Combinatorial reasoning and its assessment. In I. Gal, \& J. Garfield (Eds.), The assessment challenge in statistics education. Amsterdam: IOS Press.

Batanero, C., \& Sanchez, E. (2005). What is the nature of high school students' conceptions and misconceptions about Probability? In G. Jones (Ed.), Exploring probability in school: Chalenges for teaching and learning (pp. 241-266). Boston, MA: Springer.

Borba, R., Rocha, C., \& Azevedo, J. (2015). Estudos em raciocínio combinatório: investigações e práticas de ensino na Educação Básica. Boletim de Educação Matemática, 29, 1348-1368.

Coutinho, C., Sousa, A., Dias, A., Bessa, F., Ferreira, M., \& Vieira, S. (2009). Investigaçãoacção: metodologia preferencial nas práticas educativas. Psicologia, Educação e Cultura, $13,455-479$.

Deitel, P., \& Deitel, H. (2010). Java: como programar. Cidade: Pearson Educación.

Eizenberg, M., \& Zaslavsky, O. (2004). Students' verification strategies for combinatorial problems. Mathematical Thinking and learning, 6(1), 15-36.

English, L. (1993). Children's strategies for solving two-and three-dimensional combinatorial problems. Journal for Research in Mathematics Education, 24(3), 255-273.

English, L. (2005). Combinatorics and the development of children's combinatorial reasoning. In G. Jones (Ed.), Exploring probability in school: Chalenges for teaching and learning (pp. 121-141). New York, MA: Springer.

Godino, J., Batanero, C., \& Roa, R. (2005). An onto-semiotic analysis of combinatorial problems and the solving processes by university students. Educational Studies in Mathematics, 60(1), 3-36.

Lopes, C., \& Souza, L. (2016). Aspectos filosóficos, psicológicos e políticos no estudo da Probabilidade e da Estatística na Educação Básica. Educação Matemática Pesquisa, 18, 1465-1489.

Navarro, V., Batanero, C., \& Godino, J. (1996). Razonamiento combinatorio en alumnos de Secundaria. Educación matemática, 8, 26-39.

Pessoa, C., \& Borba, R. (2010). O desenvolvimento do raciocínio combinatório na escolarização básica. Revista de Educação Matemática e Tecnológica Iberoamericana, $1(1-22)$. 
Polaki, M. (2005). Dealing with compound events. In G. Jones (Ed.), Exploring probability in school: Chalenges for teaching and learning. New York: Springer.

Souza, L., \& Lopes, C. (2011). O uso de simuladores e a tecnologia no ensino da Estocástica. Boletim de Educação Matemática, 24, 659-667.

Submetido em: 29/03/2019

Aceito em: 06/09/2019 